REGARDS

SUR L'ECONOMIE ALLEMANDE

BULLETIN ECONOMIQUE DU CIRAC

\section{Regards sur l'économie allemande}

Bulletin économique du CIRAC

$71 \mid 2005$

Varia

\title{
Relations du travail
}

FRANKE Dietmar, Vertrauensvolle Zusammenarbeit mit dem Betriebsrat. Handlungsanleitung / LESCH Hagen, Arbeitsbeziehungen im Wandel / NIEDENHOFF Horst-Udo, Die direkten Kosten der Anwendung des Betriebsverfassungsgesetzes. Ergebnisse einer Unternehmensbefragung aus den Jahren 2003/2004

\section{OpenEdition \\ Journals}

Édition électronique

URL : http://journals.openedition.org/rea/399

DOI : $10.4000 /$ rea.399

ISBN : 978-2-8218-0838-6

ISSN : 1965-0787

Éditeur

CIRAC

Édition imprimée

Date de publication : 1 mai 2005

ISSN : 1156-8992

Référence électronique

"Relations du travail », Regards sur l'économie allemande [En ligne], 71 | mai 2005, document 7, mis en ligne le 24 avril 2008, consulté le 22 septembre 2020. URL : http://journals.openedition.org/rea/399 ; DOI : https://doi.org/10.4000/rea.399

Ce document a été généré automatiquement le 22 septembre 2020.

(c) CIRAC 


\section{Relations du travail}

FRANKE Dietmar, Vertrauensvolle Zusammenarbeit mit dem Betriebsrat. Handlungsanleitung / LESCH Hagen, Arbeitsbeziehungen im Wandel / NIEDENHOFF Horst-Udo, Die direkten Kosten der Anwendung des Betriebsverfassungsgesetzes. Ergebnisse einer Unternehmensbefragung aus den Jahren 2003/2004

\section{RÉFÉRENCE}

FRANKE Dietmar, Vertrauensvolle Zusammenarbeit mit dem Betriebsrat.

Handlungsanleitung, DATAKONTEXT-Fachverlag, Frechen, 2005, 200 p.

LESCH Hagen, Arbeitsbeziehungen im Wandel, IW-Positionen, $\mathrm{n}^{\circ} 13$, Deutscher

Instituts-Verlag, Cologne, 2004, 60 p.

NIEDENHOFF Horst-Udo, Die direkten Kosten der Anwendung des

Betriebsverfassungsgesetzes. Ergebnisse einer Unternehmensbefragung aus den

Jahren 2003/2004, IW-Analysen, Deutscher Instituts-Verlag, Cologne, 2004, 72 p.

Les relations du travail ont subi de profondes mutations outre-Rhin (LESCH) dont la principale est la 'décentralisation' de la régulation du niveau de la branche vers celui de l'entreprise. Si le partenariat social allemand résiste néanmoins, cela est dû au repositionnement en cours des organisations, mais aussi à l'attachement des salariés comme du patronat au principe de la co-décision (Mitbestimmung), facteur de paix sociale et donc de prévisibilité. Surtout, la confiance réciproque des deux parties permet de gérer sans crise les restructurations. Encore faut-il maîtriser les règles du jeu, que rappelle utilement ce manuel (FRANKE) à destination des patrons. Mais la Mitbestimmung entraîne aussi des coûts directs élevés pour les entreprises (NIEDENHOFF), qu'il s'agit de parvenir à maîtriser pour assurer l'avenir de la codécision au niveau de l'entreprise. (ib) 